\title{
DISEÑO Y ADMINISTRACIÓN DE PROYECTOS DE ROBÓTICA EDUCATIVA: LECCIONES APRENDIDAS
}

Resumen: El inicio de proyectos educativos que incluyen la robótica como recurso de enseñanza y aprendizaje requiere plantearse en función de las capacidades y desempeños que se esperan consolidar en la población meta. Estas capacidades son el punto de partida para delinear los énfasis de contenido, los desempeños deseados, las tecnologías que se necesitan, los procesos de capacitación y seguimiento que hay que diseñar. La robótica educativa es propicia para apoyar habilidades productivas, creativas, digitales y comunicativas; y se convierte en un motor para la innovación cuando produce cambios en las personas, en las ideas y actitudes, en las relaciones, modos de actual y pensar de los estudiantes y los educadores. Si esos cambios son visibles en la práctica cotidiana, entonces estamos ante una innovación porque la robótica habrá trascendido sus intuiciones y se reflejará en sus acciones y productos.

Palabras clave: Robótica educativa; administración de proyectos; habilidades y capacidades; innovación; informática educativa.

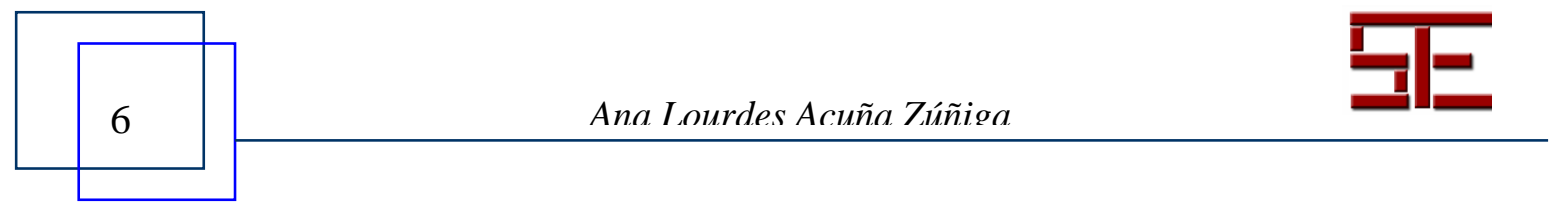




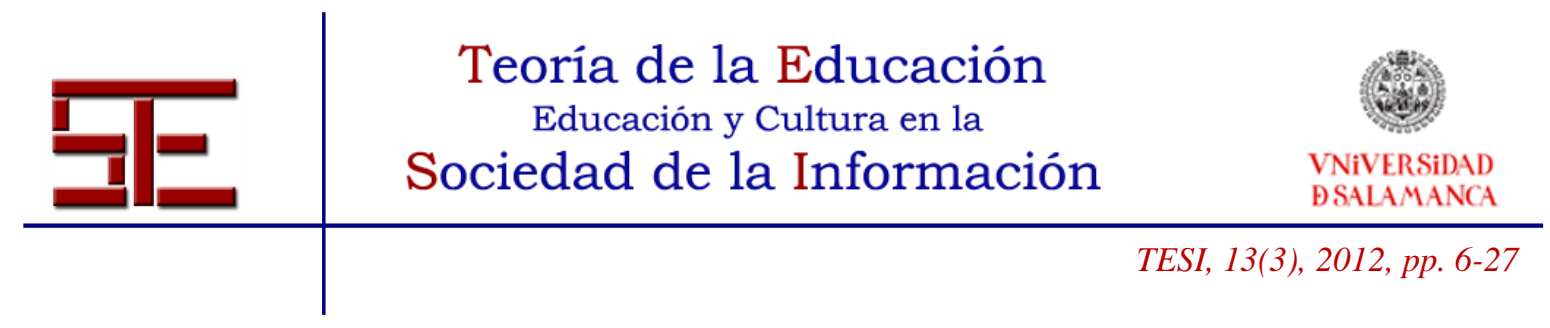

\section{DESIGN AND PROJECT MANAGEMENT ROBOTICS EDUCATION: LESSONS LEARNED}

Abstract: The educative projects that include the robotics as resource of education and learning require being plan based on the skills and performances that would consolidate in the population. These skills are the start point to delineate the content emphases, the wished performances, the needed technologies, the processes of training and searching that will be necessary to design. Particularly the educative robotics is propitious to develop or to support productive, creative, digital, communicative abilities. An indicator, that shows that robotics has become an innovation engine, is observed on the change in the people's attitude and ideas, ways of present and thinking of the students specially, when they become to socialize with others. If those changes are visible now, therefore we are getting close to an innovation because the robotics will have extended its intuitions and it is reflected in its actions and products.

Keywords: Educational Robotics; project design; abilities and capacities; computer science technology in education.

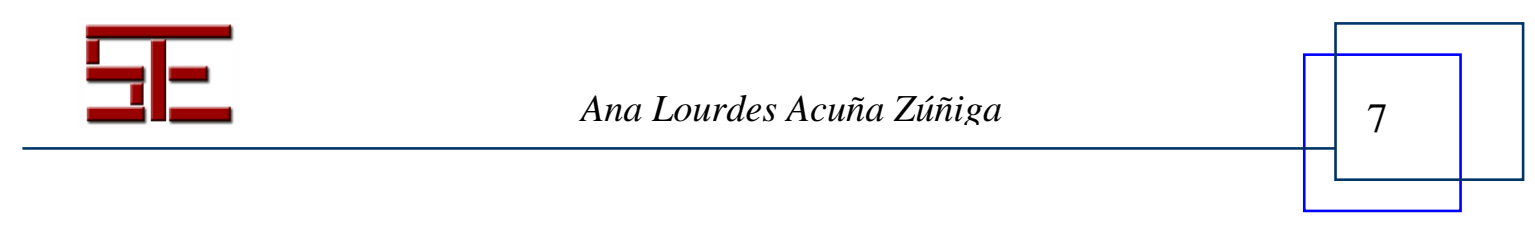




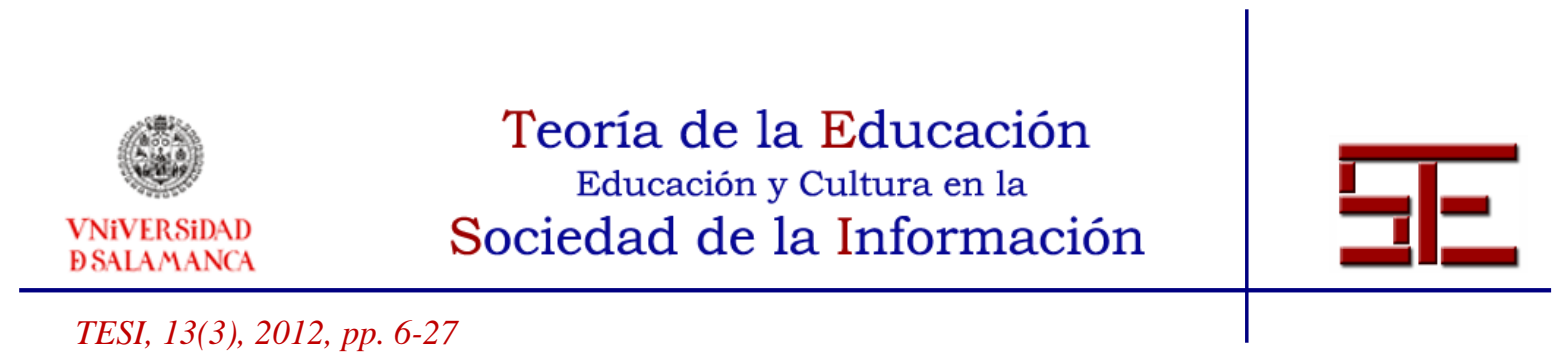

\section{DISEÑO Y ADMINISTRACIÓN DE PROYECTOS DE ROBÓTICA EDUCATIVA: LECCIONES APRENDIDAS}

Fecha de recepción: 07/05/2012; fecha de aceptación: 15/09/2012; fecha de publicación: 30/11/2012

Ana Lourdes Acuña Zúñiga

ana.acuna@fod.ac.cr

Fundación Omar Dengo. Costa Rica

\section{1.- INTRODUCCIÓN}

Es común escuchar a responsables de centros e instituciones de enseñanza y autoridades educativas, preguntar por las condiciones y requisitos para implementar proyectos educativos que incluyan la robótica. Al indagar sobre estas necesidades nos encontramos que, en la mayoría de los casos, los deseos por implementar robótica surgen por el impulso que marcan los avances tecnológicos o por una necesidad de insertar agentes tecnológicos innovadores para ganar reconocimiento social.

Preocupada por las repercusiones que esos impulsos puedan tener, si se concretan proyectos que atienden esas premisas, reuní en este artículo las lecciones aprendidas a partir de la experiencia de varios años liderando proyectos de robótica educativa en Costa Rica y que podrían ser buenos insumos para que otros países o personas las usen como marco de referencia en la ejecución de proyectos educativos similares.

Inicio con los conceptos de robótica y proyecto educativo, luego comparto las lecciones aprendidas que se desprenden de los proyectos de robótica educativa de la Fundación Omar Dengo, así como los desempeños y habilidades observadas en estudiantes durante esas experiencias. Finalizo con algunas reflexiones acerca de la robótica como innovación educativa

\section{2.- ROBÓTICA EDUCATIVA}

En el marco de nuestra experiencia concebimos la robótica educativa como un contexto de aprendizaje que promueve un conjunto de desempeños y habilidades directamente vinculados a la creatividad, el diseño, la construcción, la programación y divulgación de creaciones propias primero mentales y luego físicas, construidas con diferentes

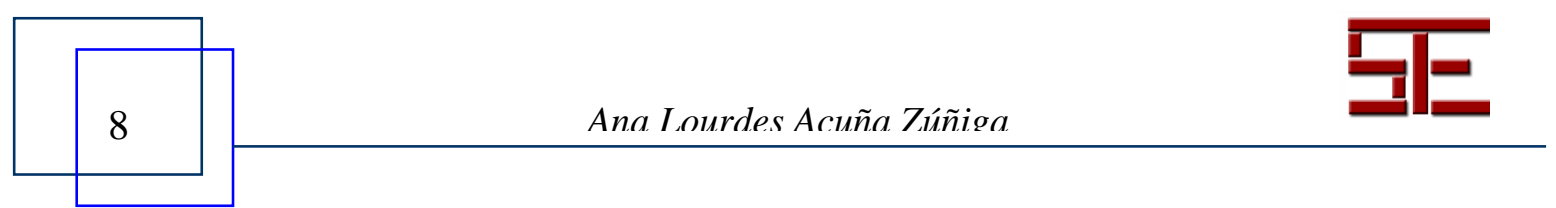




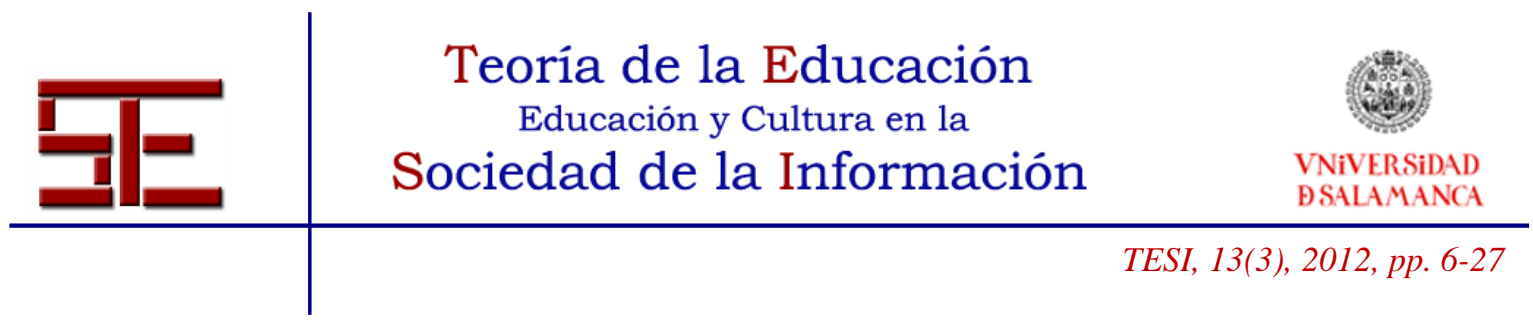

materiales y recursos tecnológicos; que pueden ser programados y controlados desde un computador o dispositivo móvil.

Estas creaciones robóticas poseen cuerpo, control y razonamiento, regularmente surgen a partir de referentes reales que la cotidianidad brinda y que son recreados como simulaciones o resultan de la imaginación y creatividad de las personas como productos originales conocidos como prototipos. Por ejemplo, en una simulación se pueden recrear procesos industriales automatizados, eventos sociales o culturales, sitios o ambientes en los que se muestran la apariencia y funcionamiento de las máquinas, las formas de movimiento o de interactuar con el ambiente de los objetos o actores, los productos que surgen y sus formas de comercialización. Por su parte, los prototipos son óptimos para proponer modelos que resuelven problemas en un tiempo o espacio determinado o que muestran nuevas creaciones que facilitan el trabajo y las formas de vida. Igualmente las producciones de los estudiantes o de sus creadores podrían integrar ambas: prototipos y simulaciones.

\section{3.- PROYECTO EDUCATIVO}

Entenderemos por proyecto educativo, el conjunto de experiencias que involucran enseñanza y aprendizaje en un área de contenido particular, que se ejecutan en un conjunto de instituciones de un país, una región o incluso internacionalmente y que atienden ejes rectores, legislativos, metodológicos y didácticos similares. Es decir, un proyecto educativo reúne un conjunto de instituciones que ejecutan la misma propuesta pedagógica y administrativa en función del logro y consolidación de ciertos aprendizajes en la población meta que benefician.

Este tipo de proyectos es común encontrarlos a la sombra de programas nacionales o políticas educativas de ciudades o países. Por ejemplo: Proyecto World Links ${ }^{1}$, Ciber@prendiz ${ }^{2}$, Intel Educar para el futuro ${ }^{3}$, que son proyectos asociados a la informática educativa que se ejecutan internacionalmente. En el caso particular de la robótica educativa, en América no se conocen proyectos a nivel internacional, pero sí existen iniciativas nacionales que benefician poblaciones en todos sus estados, como es el caso de Costa Rica o nivel estatal o en algunas ciudades como México DF, Brasilia, Santiago de Chile, Bogotá-Colombia y en varios estados de Estados Unidos.

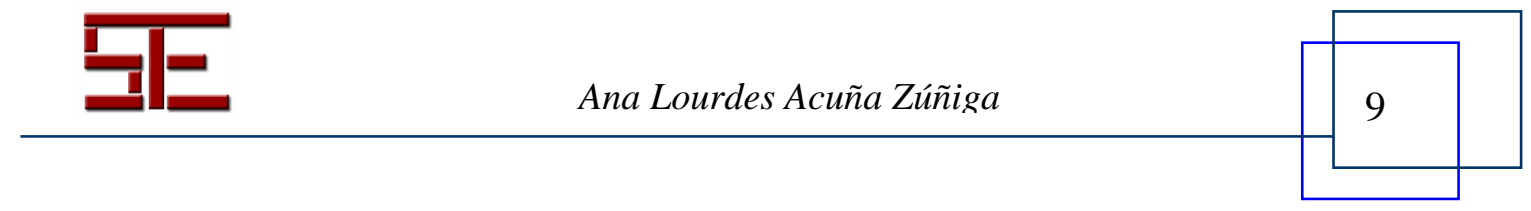




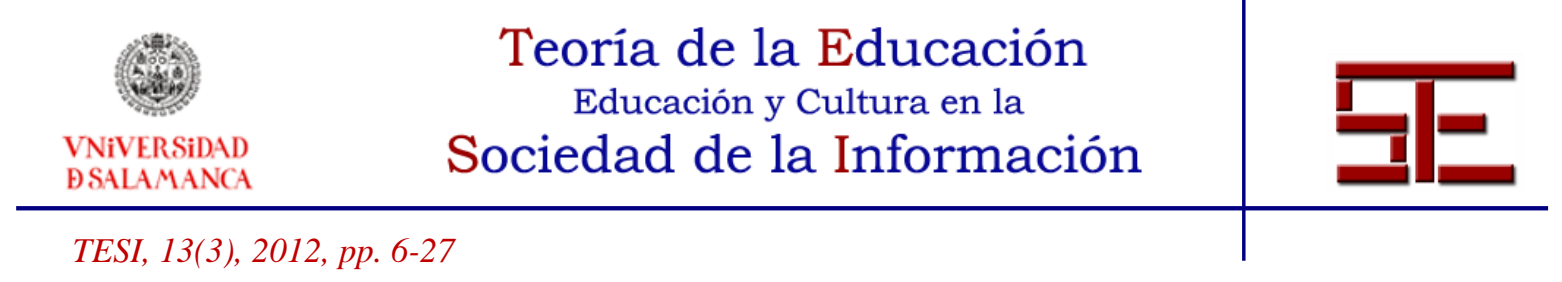

\section{4.- ROBÓTICA COMO PROYECTO EDUCATIVO}

No hay duda de que la robótica educativa se posiciona en estas épocas como un elemento nuevo y necesario de conocer por las nuevas generaciones. Las empresas de industria han incorporado procesos de producción y múltiples elementos que incluyen automatismos y control. Los ingenieros mecánicos, electrónicos y más recientemente los informáticos han asumido estos desarrollos. Sin embargo, en las últimas décadas se muestra con mayor presencia la necesidad de formarse u obtener alguna especialidad que abarque con mayor profundidad esos temas. Surgiendo así la robótica como un área de estudios a nivel universitario. Paralelo a esto, nacen desarrollos y nuevas tecnologías que intentan acercar estos conocimientos a niños y jóvenes impulsando a las escuelas a insertarlos como recursos de apoyo en los procesos de enseñanza de sus estudiantes.

Estos desarrollos y avances mundiales justifican las necesidades creadas por el exterior para que las instituciones educativas quieran incorporar la robótica, pero no son suficientes ni sostenibles en el tiempo, si se valora la rapidez de los cambios tecnológicos actuales. Por lo tanto, una primera razón para proponer un proyecto educativo con robótica debería estar ligada al beneficio que los estudiantes obtendrán de él. Por lo tanto, será necesario pensar en las habilidades sociales, cognitivas y tecnológicas a favorecer y los niveles de apropiación que se promoverán desde esa iniciativa.

"Apropiarse de algo significa hacerlo propio hasta el punto de poder aplicarlo a conveniencia y según los requerimientos y características de situaciones específicas." (Perkins, 2006: 2). Partiendo de esta premisa, en el campo de la robótica educativa debemos preguntarnos por aquellas habilidades o desempeños que deseamos que los estudiantes se apropien y, en función de ellos, crear, diseñar y disponer los contextos de aprendizaje para facilitarlos.

En la actualidad se implementan diversas experiencias en robótica educativa cuyos énfasis son muy variados. Por ejemplo:

- La construcción de robots que compiten según sus habilidades o capacidades de movilidad y discriminación de información. Existen reglas de competición que los estudiantes o instituciones conocen y previo a la competencia los estudiantes trabajan apoyados por sus maestros o un tutor, en el cumplimiento de los

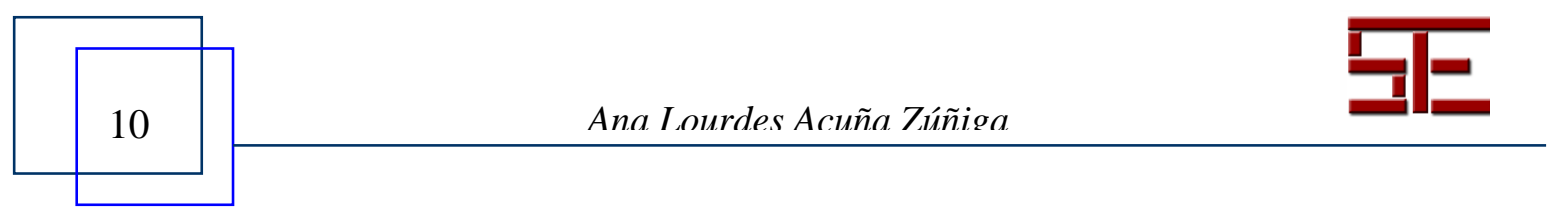




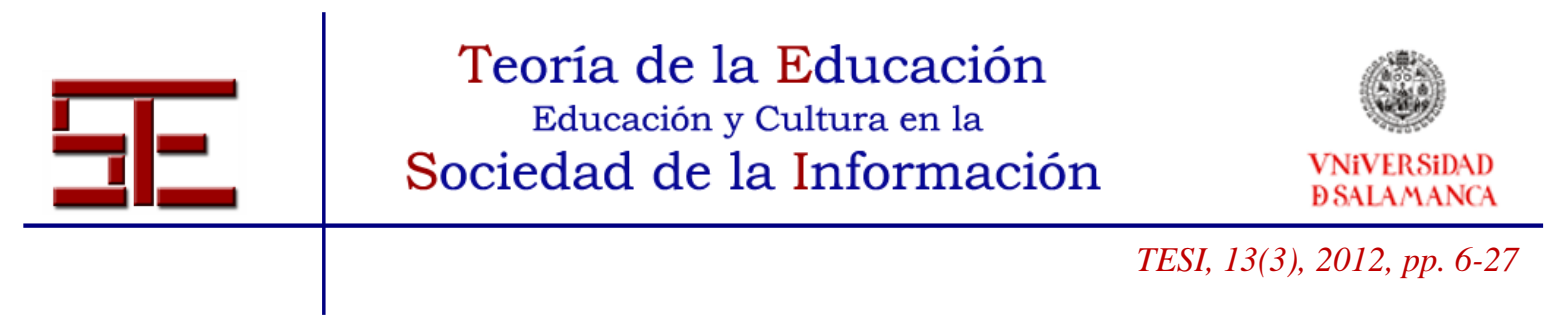

requisitos. En esta modalidad tenemos, por ejemplo: la First LEGO League ${ }^{4}, \quad$ y la Robot World Cup Initiative ${ }^{5}$, la que se celebran todos los años.

- La robótica para el apoyo curricular, en la cual las instituciones cuentan con laboratorios o ciertos recursos de robótica que los estudiantes manipulan en sus salones de clase para recrear modelos o construir prototipos que demuestran ciertas leyes o comportamientos físicos. Por ejemplo: NASA Robotics Education Project ${ }^{6}$.

- Iniciativas que apoyan el desarrollo de ciertas habilidades o capacidades como la creatividad, el diseño, la manipulación de conceptos básicos en robótica. Generalmente se desarrollan en plazos y tiempos particulares como cursos de verano, son grupos pequeños y regularmente están asociados a experiencias de investigación, para probar algún dispositivo o estrategia didáctica particular. Tal es el caso de Robotic Desig Studio de la Wellesley College en Boston?

- Proyectos educativos con robótica que cuentan con una propuesta pedagógica claramente establecida y difundida en las instituciones que participan. Estos proyectos se caracterizan por su permanencia en el tiempo y su crecimiento, evolución e innovación constante con un contexto político, administrativo y financiero que les respalda, como es el caso del proyecto de Robótica y Aprendizaje por diseño en Costa Rica ${ }^{8}$.

En el caso de la experiencia de Costa Rica el proyecto educativo de robótica es liderado por el Área de Aprendizaje Lógico, Científico y Robótica de la Fundación Omar Dengo en conjunto con el Ministerio de Educación Pública de Costa Rica, en el marco del Programa Nacional de Informática Educativa MEP-FOD. El proyecto se inició en 1998 y beneficia a estudiantes de las escuelas públicas de I y II Ciclos de la Enseñanza General Básica (EGB) y colegios públicos (III Ciclo de la EGB).

Esta iniciativa centraliza su acciones en la concreción de ciertos desempeños y habilidades en los estudiantes relacionado con el diseño tecnológico, como son; el trabajo por proyectos para el diseño de prototipos y simulaciones; la resolución de problemas; la comprensión y simulación de procesos de producción o industriales; el diseño, control y automatización de mecanismos; la evaluación de productos, y la socialización de resultados. Procurando así, crear puertas y visiones nuevas en los estudiantes, no sólo en los aspectos que caracterizan la robótica, sino en la generación de contextos y ambientes de aprendizaje óptimos para la creación, la innovación y propulsores de ideas y valores que puedan ser trasladados a la cotidianidad.

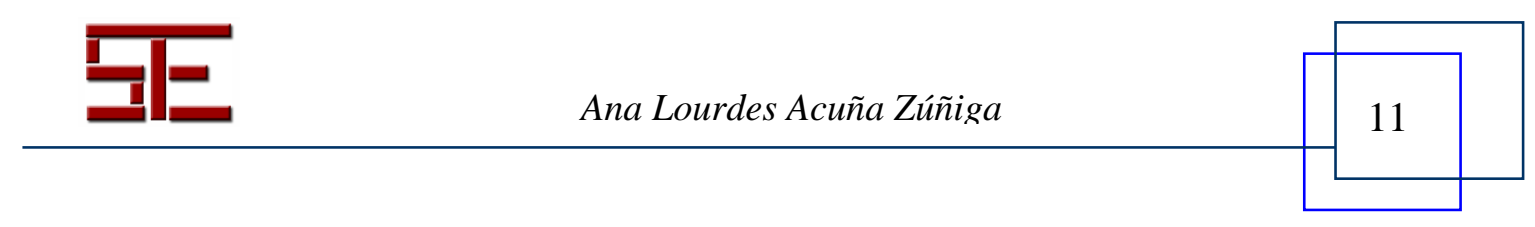




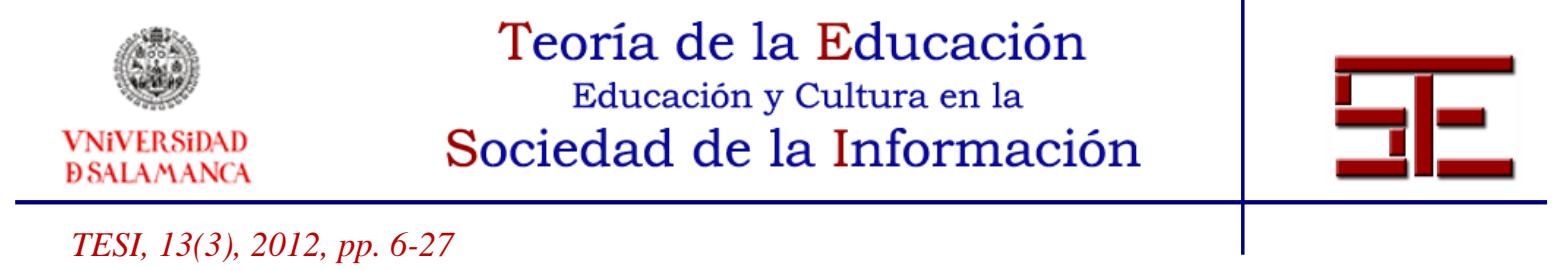

Los grupos participantes de primaria se involucran en el desarrollo de proyectos que simulan sitios, lugares o eventos cercanos a sus comunidades. El propósito educativo de esta experiencia es promover la creación de una generación de niños y niñas sensibilizados con el desarrollo actual de la ciencia y la tecnología y conscientes del potencial creativo y de aprendizaje que poseen. Ellos estudian procesos, eventos y sitios, luego los recrean y simulan haciendo uso de la robótica. Dos preguntas poderosas orientan el proceso de aprendizaje: ¿Cómo funcionan las cosas? y ¿Por qué pasa lo que pasa? Sus producciones se publican y comparten con la comunidad escolar y en la Internet vía web. La experiencia se identifica con el nombre "Salas de exploración con robótica".

En la enseñanza secundaria el proyecto se llama Talleres de Solución Creativa con Robótica. Su propósito es involucrar a los jóvenes en el desarrollo de proyectos fundamentados en la detección, evaluación y solución de problemas de sus comunidades. Estas soluciones incluyen el diseño, la construcción y programación de prototipos de solución a los problemas investigados, utilizando las tecnologías digitales. Los resultados y productos realizados se dan a conocer a las comunidades, en encuentros formales que los estudiantes y educadores organizan. Los grupos de 15 estudiantes realizan sus investigaciones a lo largo de un semestre y publican sus productos en la WEB.

\section{5.- LECCIONES APRENDIDAS}

Los proyectos educativos con robótica se iniciaron en Costa Rica a partir de 1998, desde entonces y hasta la fecha, hemos acumulado un conjunto de aprendizajes acerca de la administración, pedagogía e impacto de este proyecto que nos permite delinear las condiciones, políticas y apoyos que deberían recibir las experiencias nuevas si desea crecer y madurar con solidez. Entre los aspectos relevantes a considerar se encuentran: un marco pedagógico sólido y de fácil comprensión, una caracterización del ambiente de aprendizaje que detalle las formas de relación entre las personas y éstas con los recursos, un proceso de capacitación acorde con la evolución tecnológica y educativa, un proceso de seguimiento sostenido y permanente, un respaldo político y financiero justo que permita crecer e innovar acorde con las sugerencias de los procesos evaluativos que se gesten.

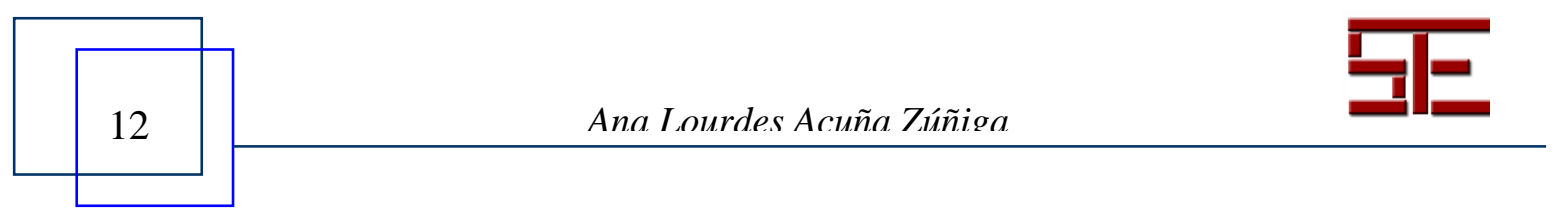




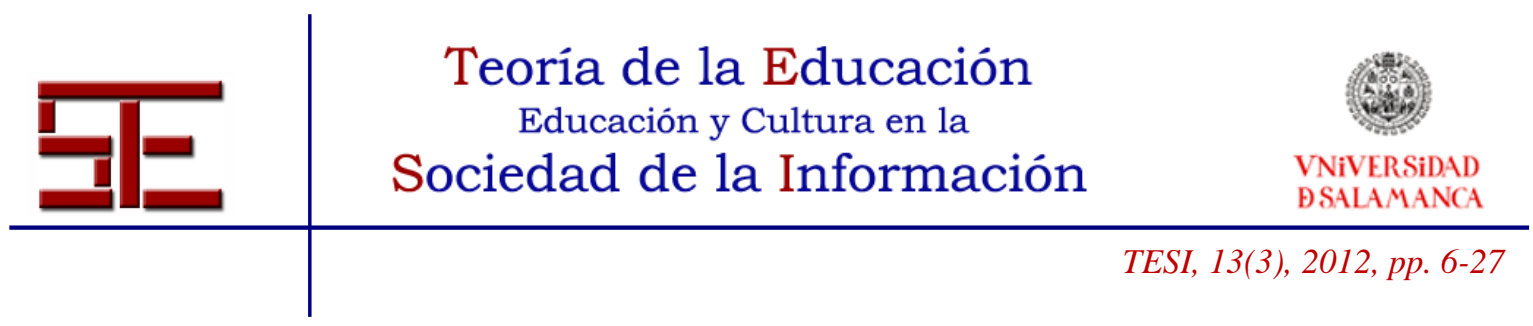

\section{1.- Marco pedagógico}

Todo proyecto educativo debe enmarcar su funcionamiento y accionar a la luz de un marco pedagógico elocuente y fácilmente comprensible para quienes tienen la tarea de ejecutarlo. El enfoque o marco pedagógico extrae y coloca como derroteros los ejes epistemológicos sobre los cuales el proyecto educativo va a conducir sus esfuerzos y con los cuales valorará su impacto y alcance.

Basados en el construccionismo de S. Paper (2003: 151-169), quien plantea la necesidad de crear ambientes de aprendizaje que apoyen la "Construcción mental", es decir, que promuevan la creación de construcciones en el mundo como apoyo de las que se producen en la cabeza; nuestro marco pedagógico coloca al estudiante como el actor principal del proceso de aprendizaje y al educador como facilitador de ese proceso. Nuestros ejes pedagógicos se concentran en promover el "Diseño - Aprendizaje, Comunicación - diversidad; Cognición-acción" (Acuña 2003: 2).

Su implementación se logra a partir de la estrategia metodológica del enfoque de aprendizaje basado en proyectos (EAP). Porque la estrategia es clara y el contenido con el cual se puede trabajar es ilimitado, por lo tanto, los intereses particulares de los estudiantes pueden ser atendidos sin dificultad y conducirlos hacia comprensiones más profundas y particulares. Pero quien la adopte, está obligado a delimitar los desempeños deseados y los productos esperados. De lo contrario, el EAP quedaría reducido a una simple metodología.

Los contenidos que los estudiantes abordan en los proyectos de robótica educativa, los hemos pulido regularmente. En los primeros años del proyecto, procurábamos que los estudiantes escogieran una temática particular que deseaban estudiar y luego se les apoyaba para que construyeran una representación con robótica que mostrara parte de ese aprendizaje. Por las facilidades que brindan los recursos del mercado para hacer construcciones y programaciones (por ejemplo el LEGO), los estudiantes optaban por proyectos que se representaban (construían y programaban) fácilmente como máquinas u objetos aislados y sin relación con respecto a otros creados por los estudiantes de su mismo grupo, por ejemplo:

Diseñaban, construían y programaban diferentes tipos de vehículos, animales, máquinas, pero no creaban relaciones o interacciones entre ellos. En su mayoría eran objetos independientes y aislados a los que se les definía un comportamiento pero

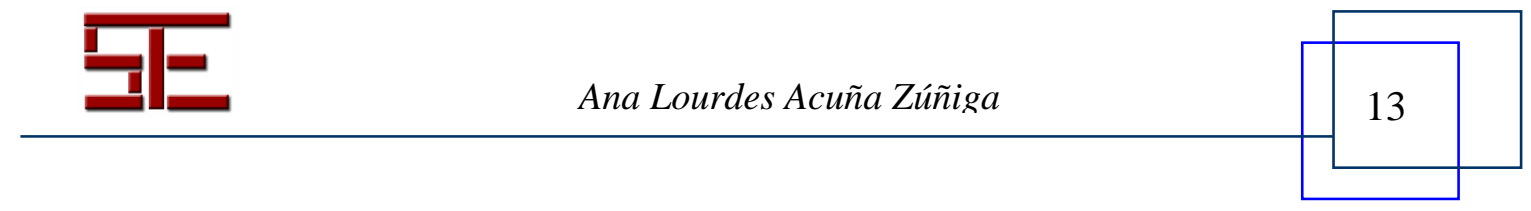




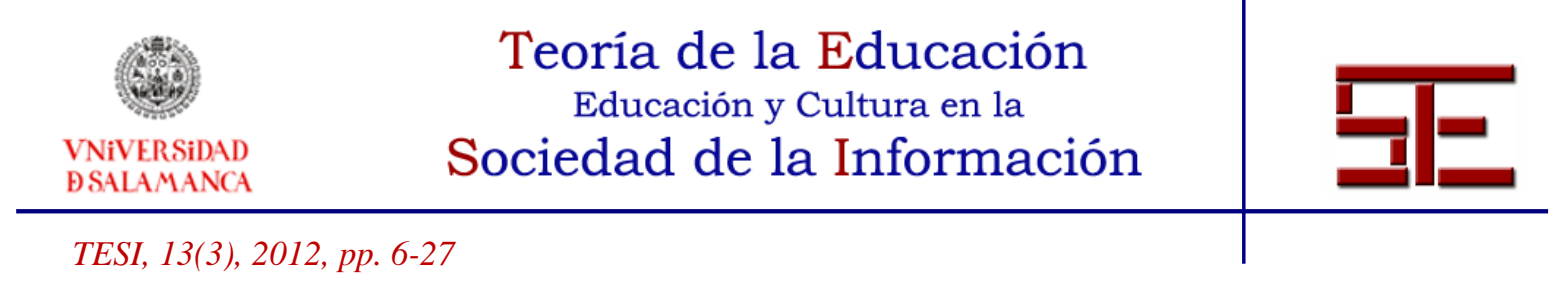

ninguna relación con el contexto donde se ubicaban o existían. Por ejemplo: vehículos, aves, reptiles, mamíferos sin determinar las características de su clase o grupo.

Preocupados por estas tendencias, en las que había robótica en los productos (objetosmovimientos- ciertos grados de inteligencia desde la programación), pero poca incidencia en las formas de pensamiento y comprensión temática en los estudiantes; nos dimos a la tarea de promover aprendizajes más integrales; que involucrarán aspectos relacionados con la cotidianidad, pero además condujeran y trascendieran las meras representaciones robóticas sin sentido. Iniciamos un trabajo con los educadores, para reorientar mejor la elección, definición y estudio de los temas que los estudiantes estaban escogiendo y trabajamos en las estrategias metodológicas que ellos podrían diseñar para orientar los procesos de aprendizaje hacia la profundización y las áreas de la robótica que había que adquirir fluidez.

Delimitamos las áreas temáticas a partir de una valoración desde la práctica, consiguiendo que los proyectos se concentraran en la simulación, comportamiento y funcionamiento real de procesos industriales y productivos, de sitios, de eventos o sobre la resolución de problemas comunales. A partir de esa delimitación nos hemos encontrado proyectos como los siguientes:

- Simulación de las etapas principales para transformar una materia prima en producto.

- Factores que deben ser considerados para la creación de un sistema de seguridad comunal.

- Incidencia de la basura en la salud y ornato de la comunidad.

- Los animales en peligro de extinción en la comunidad.

- Ciclo de vida de los pingüinos en el Ártico.

Con estas estrategias hemos logrado que los estudiantes tengan mejores niveles de comprensión relacionados con los temas y muestren mejores representaciones en sus construcciones y programaciones, al tener un referente real sobre el cual están trabajando e intentando simular.

En el área de la robótica los estudiantes simulan con sus productos los comportamientos de los objetos recreados, procurando que éstos sean programados según las realidades o

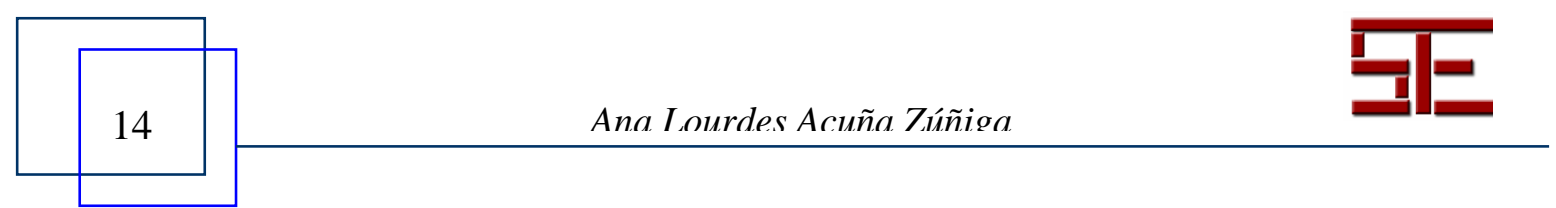




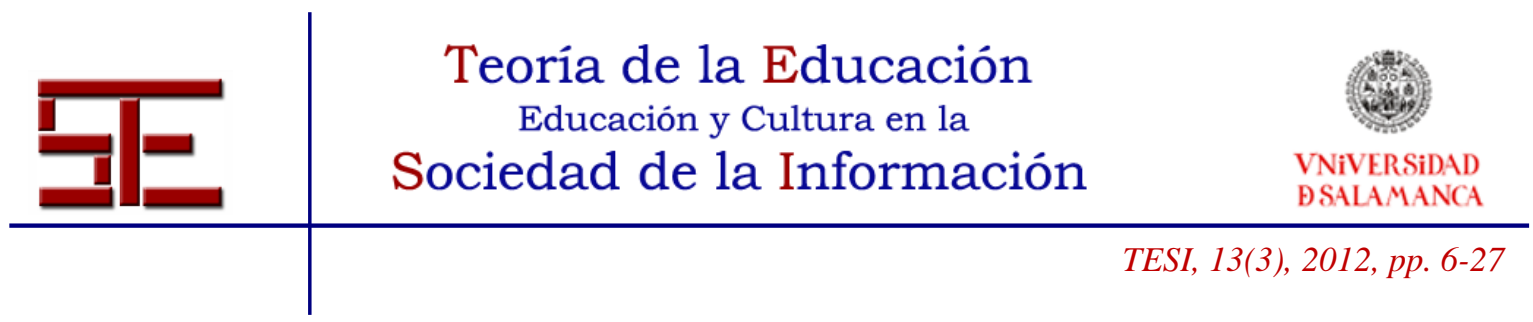

comportamientos conocidos o investigado, por ejemplo, reacciones hacia la luz y el ambiente si están trabajando los animales nocturnos; automatismos y estructuras acopladas atendiendo la escala o respetando las dimensiones reales o proporcionales entre ellas si están simulando procesos de producción o hábitats; coordinación entre los movimientos y mecanismos que han construido y programado si se trata de la recreación de un sitio.

En el mismo sentido, resulta muy funcional trabajar con el "gran grupo", todos los estudiantes en un único proyecto, esto permite la distribución de tareas y responsabilidades y mejores niveles de profundización y comprensión en el tema que se está estudiando. El tema es propuesto por los estudiantes e investigado por todos. En conjunto determinan las partes o secciones relevantes que se van a recrear y se organizan en subgrupos para estudiar e investigar a profundidad las secciones que les correspondió, así cada subgrupo recreará la parte del proceso, sitio, evento o solución al problema que está investigando.

Estas estrategias de especialidad subgrupal mejoran los niveles de compromiso que los estudiantes tienen respecto a sus producciones porque son únicas y sólo ellos lo han investigado y les obliga a coordinarse con otros subgrupos, para poder hace coincidir sus construcciones y sistemas de control. Requieren, entonces, coordinar, llegar a consensos, resolver desajustes y muchos problemas que surgen al tratar de acoplar la producción de 4 o 5 grupos que integran hasta 20 estudiantes en un mismo grupo. En síntesis, no es lo mismo construir un objeto de un sistema, que crear el sistema respetando sus dimensiones, relaciones e interacciones entre los objetos o partes que lo integran.

Con este tipo de propuestas los conocimientos correspondientes a la robótica saltan por su propio peso. Resulta obligado insertar sistemas de engranes y estudiar su teoría para poder lograr los efectos de velocidad y fuerza requeridos, es decir, los estudiantes deben comprender la teoría de las maquinas compuestas y simples, para poder aplicarlas y usarlas sin restricciones en sus creaciones. Es necesario programar estructuras condicionales pues sin ellas no es posible simular comportamientos que se vean afectados por el ambiente. Se requiere trabajar las estructuras de los objetos a escala y cuidar los acoples pues de lo contrario sería imposible el ensamble de todas la partes en una sola estructura.

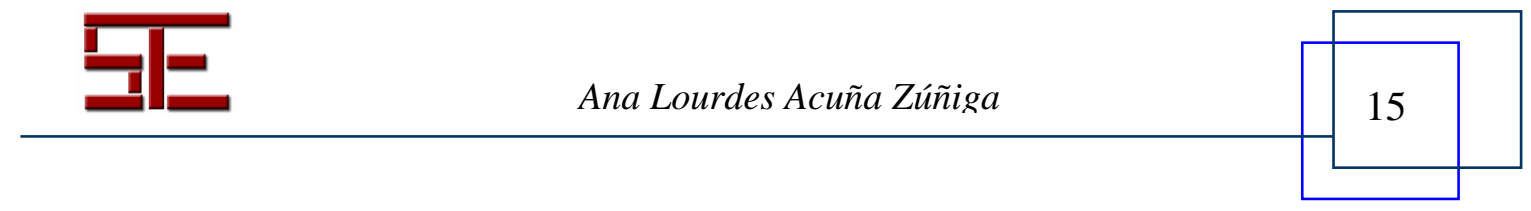




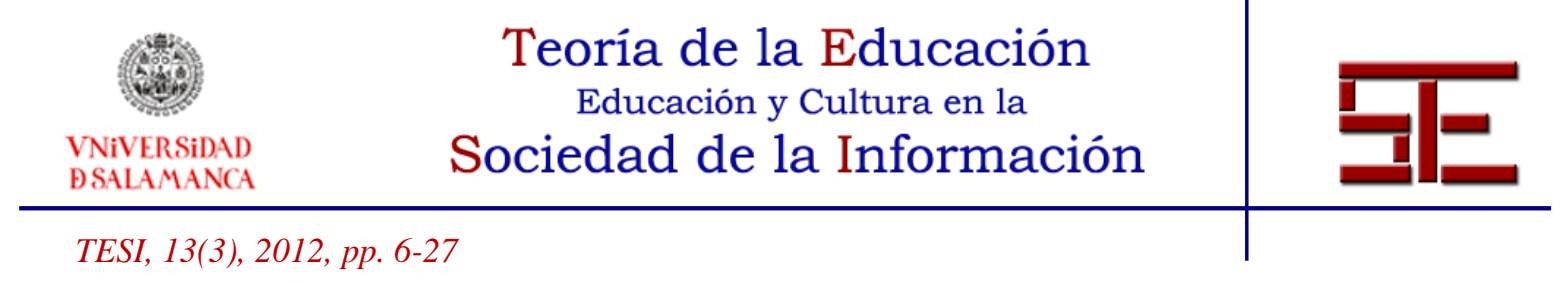

En resumen, nos concentramos en el fortalecimiento de habilidades que tienen posibilidad de ser descubiertas o mejoradas desde la práctica y en la creación de producciones que surgen de un proceso de diseño propio, como son: el planeamiento, la creatividad, la valoración de productos, el automatismo y control, la resolución de problemas, entre otras. La robótica es un recurso ideal para facilitar el aprendizaje, pero no es un fin en sí misma en nuestros proyectos educativos.

\section{2.- Ambiente de aprendizaje}

Entendemos por ambiente de aprendizaje las relaciones e interacciones que ocurren en el aula entre los estudiantes y educadores, y entre ellos con los recursos. Por lo tanto, el ambiente de aprendizaje al igual que los lineamientos pedagógicos deben preverse y organizarse en función de las habilidades o desempeños deseados.

Un factor muy importante de este rubro es la población a beneficiar. Las tendencias históricas que marcan los procesos de enseñanza actuales inciden en la conformación de los grupos de estudiantes, estableciendo procesos de enseñanza, según edad y madurez. Sin embargo, la experiencia en la ejecución de proyectos con robótica nos ha demostrado que aquellos grupos que integran estudiantes de diversas edades, procedencias y estados de madurez resultan más productivos y creativos que los conformados con ciertas uniformidades.

En realidad, la diferencia en los procesos de aprendizaje en el área de la robótica parece estar definidos por la oferta pedagógica de que se disponga. Así, proyectos que requerirán mayores niveles de profundización y estudio o investigación resultarán más difíciles para estudiantes que no poseen experiencia y conocimiento en esas áreas. Por lo tanto, lo mejor es respetar la diversidad y adecuar la propuesta según las capacidades que muestren o vayan desarrollando los estudiantes y no unificar las propuestas para que sean los estudiantes quienes tengan que adaptarse a ellas.

Otras variables a tener en cuenta en el ambiente de aprendizaje que se adopte para el proyecto educativo,son la población meta a beneficiar y la cantidad de recursos tecnológicos que se requiere para su ejecución.

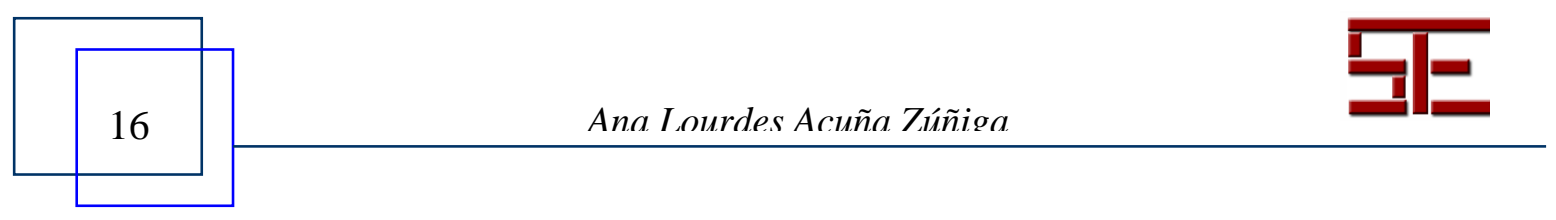




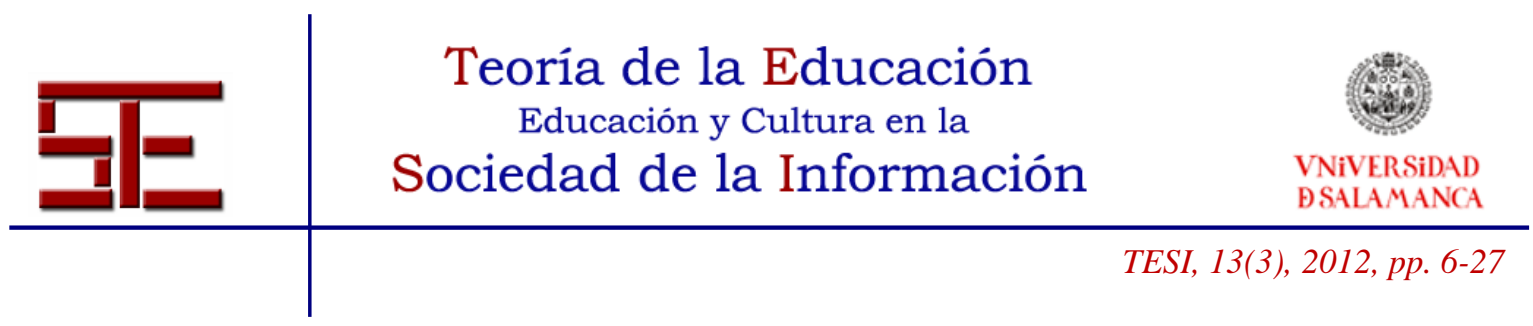

\subsubsection{Recursos tecnológicos}

Cómo anticipar cuánto equipo y de qué características debe ser conforman las preguntas más frecuentes en este tema de selección de los recursos tecnológicos que se necesitan. Sin embargo, hay otros factores a considerar en simultáneo que deben analizarse, por ejemplo:

Si los productos que los estudiantes estarán creando o construyendo involucran la totalidad del grupo, es fácil anticipar que habrá mucha demanda de recursos de robótica para construir estructuras. Si no se desea enfrentar limitaciones por falta de recursos o tener que limitar los productos que los estudiantes hacen a las existencias de equipo que se tenga, entonces habrá que organizar modalidades de atención en periodos continuos y en el largo plazo. Por ejemplo: varias lecciones semanales durante algunos meses para el mismo grupo. Es importante recordar que en robótica no es posible desarmar y armar en cada lección porque una construcción y su control es algo muy similar a la creación de una obra artística, algo parecido a una escultura o una maqueta. Estas requieren tiempo para mejoras, ajustes y detalles.

A diferencia del caso en que la creación de proyectos educativos esté asociada a pequeños modelos que representan o ayudan a comprender ciertas leyes físicas o científicas. Es decir, proyectos con un énfasis demostrativo que son usados por los estudiantes para obtener evidencias sobre alguna teoría particular. En este caso es probable que la demanda de recursos tecnológicos no sea tan excesiva y probablemente resulte más fácil armar y desarmar las estructuras en plazos más cortos.

Independientemente del tipo de proyecto que se oferte el factor de los recursos tecnológicos es esencial y hay que tener claridad de lo que es indispensable y de lo que qué no es. Es decir, cuáles equipos o materiales pueden ser sustituidos por otros de menor costo y cuáles deben adquirirse. Por ejemplo, los controladores (Arduino NXT, RCX, Handy Cricket, GOGO Board, Pico Cricket,) son equipos que deben adquirirse y la cantidad a comprar dependerá de la cantidad de máquinas de que se dispone y del número de estudiantes a atender.

Los motores, sensores, luces sirenas, por su parte, al igual que otros componentes, se podrán definir según la cantidad de puertos y capacidad de conexión que tengan las interfaces y de acuerdo al tipo de proyecto que se anticipa proponer; por ejemplo, ciertos tipos de sensores son indispensables para procesos de investigación en la captura

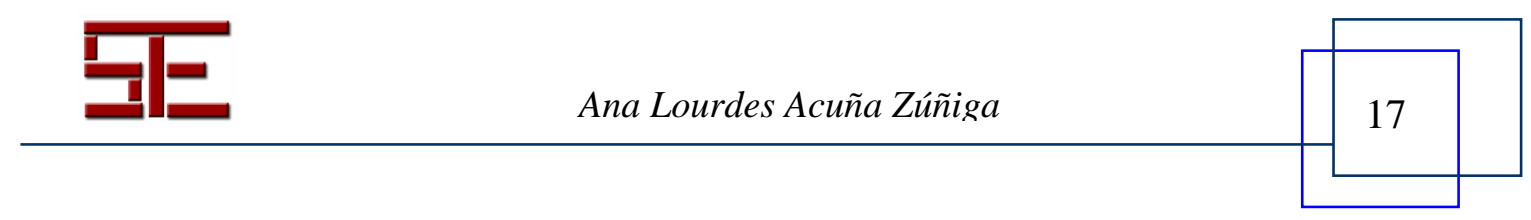




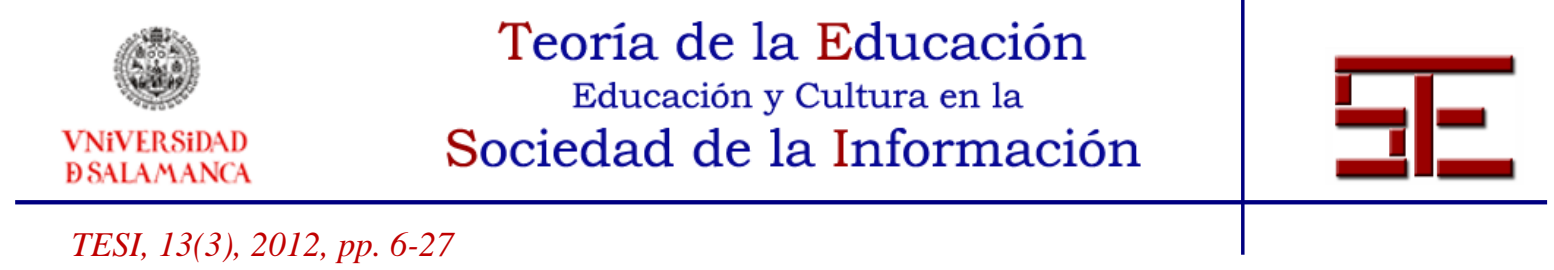

de datos, tal el caso de los sensores de resistencia, distancia, temperatura, color, rotación, por citar algunos.

Los recursos para crear estructuras, como paredes, bases, techos, son variables, y existen en el mercado múltiples soluciones para crear estos detalles, desde: balsa, Legos, cartón, hasta materiales rehusados tomados de cajas de cereales, juguetes en desuso, plásticos variados.

Si la propuesta tiende a impulsar la inserción y construcción de mecanismos usando una buena gama de máquinas compuestas, como es nuestro caso, entonces debe disponerse de mucho recurso de esta índole como son: engranes de diferentes tamaño y funciones; ejes, tornillos, bielas, poleas y todas sus variantes. Así como las opciones estructurales que garanticen su ensamble, por ejemplo, ejes de diferente tamaño y cajas o barras de acople para hacer los mecanismos, los sistemas de engranajes y las máquinas.

En cuanto a la construcción de mecanismos, igual se puede optar por usar trenes de engranes recuperados de equipos electrónicos o tecnológicos en desuso, como son: unidades de CD, juguetes de control, engranes de impresoras, escáner u otros. Si este es el caso, entonces será necesario agregar a los materiales de la sala: herramientas que permitan desarmar, cortar, soldar y pegar. Como alicates, cautines, seguetas, destornilladores, taladros y otros.

\subsubsection{Recurso humano}

Otro factor relevante en el ambiente de aprendizaje de un proyecto educativo con robótica es el educador o profesional que mediará o facilitará los aprendizajes junto con los estudiantes. Una característica muy importante de esa persona es la disposición o actitud positiva que muestre hacia la tecnología y el aprendizaje. Este profesional debería destacarse por el gusto hacia el estudio constante de la evolución tecnológica, lo innovador, las máquinas, los automáticos, los robots y su comportamiento. Igualmente debería disfrutar de la programación y aunque no tenga el conocimiento mostrar interés y la mejor disposición para aprender. Tenderá a ser una persona creativa y dispuesta al cambio, a las complicaciones surgidas por problemas de programación, construcción, acople de estructuras y desacuerdo entre los estudiantes, etc. Pero, ante todo, deberá poseer vocación hacia la enseñanza y disfrutar el gusto de compartir lo que sabe y estar dispuesto a aprender de y con sus estudiantes. Es decir, su

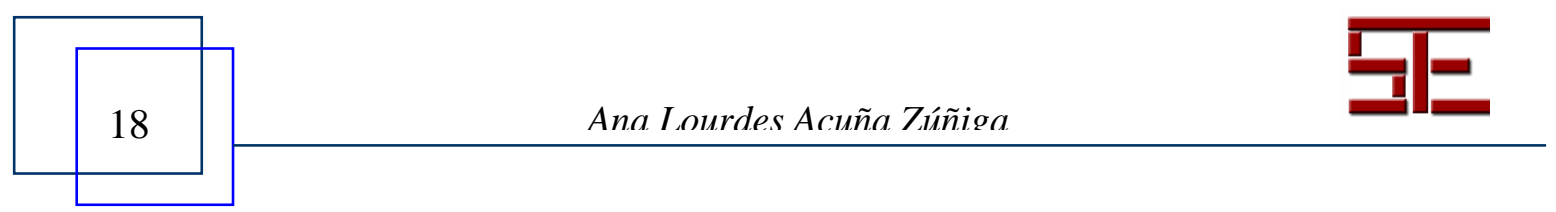




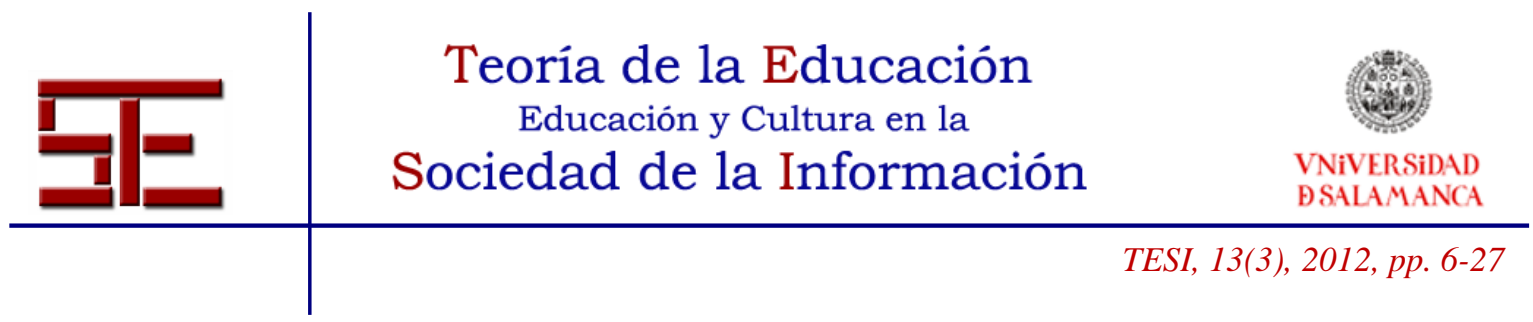

mayor cualidad será la de generar y aprovechar todos los momentos para construir y facilitar la construcción de aprendizajes propios y ajenos.

\section{3.- Capacitación}

Si los profesionales no cuentan con una especialidad en robótica, entonces el proyecto educativo para el cual laboran o participarán, deberá asumir este proceso de capacitación. Generalmente las personas con formación en informática educativa, ciencias, ingeniería, computación se desempeñan muy bien en esta área. Lo ideal es contar con profesionales que posean ambas especialidades de estudio, la informática o ingeniería y la educación y con algún curso o conocimiento previo en robótica.

La capacitación, pilar de todo proyecto educativo, toma forma y contenido en función de las habilidades que el proyecto busca desarrollar. En Costa Rica ante la ausencia de la especialidad universitaria en robótica educativa, el Área de Aprendizaje Lógico, Científico y Robótica de la Fundación Omar Dengo es la responsable del diseño, ejecución y evaluación de los procesos de capacitación en que participan, educadores de primaria y de secundaria. Los énfasis y planteamientos se han creado en función de las necesidades del proyecto. Para su planteamiento se ha considerado lo siguiente:

El perfil inicial y formación académica de los educadores que empiezan y los que permanecen.

Los contenidos necesarios por enseñar que el educador debe conocer para ejecutar la propuesta pedagógica.

Las características de los recursos tecnológicos que cada proyecto tiene.

Los tiempos de ejecución presencial y en línea que se requieren.

Las estrategias más efectivas que permiten consolidar mejores comprensiones en los estudiantes respecto los temas y en robótica.

Según nuestra experiencia, los grupos para capacitación no deben ser muy grandes si se desean propósitos y resultados específicos a conseguir. Los grupos de 20 personas son ideales si se cuenta con recursos tecnológicos suficientes para trabajar en parejas o individualmente. Propuestas de capacitación que simulan las ejecuciones y resultados esperados según la propuesta pedagógica del proyecto educativo son más efectivas, si se desea que ellos pongan o lleven a la práctica los conocimientos en un corto plazo.

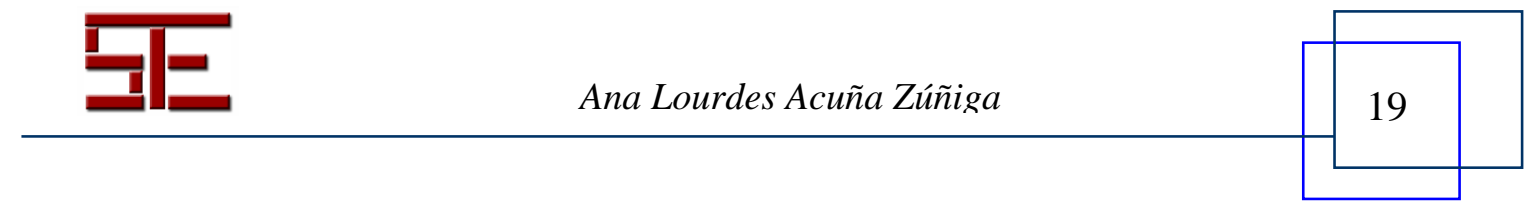




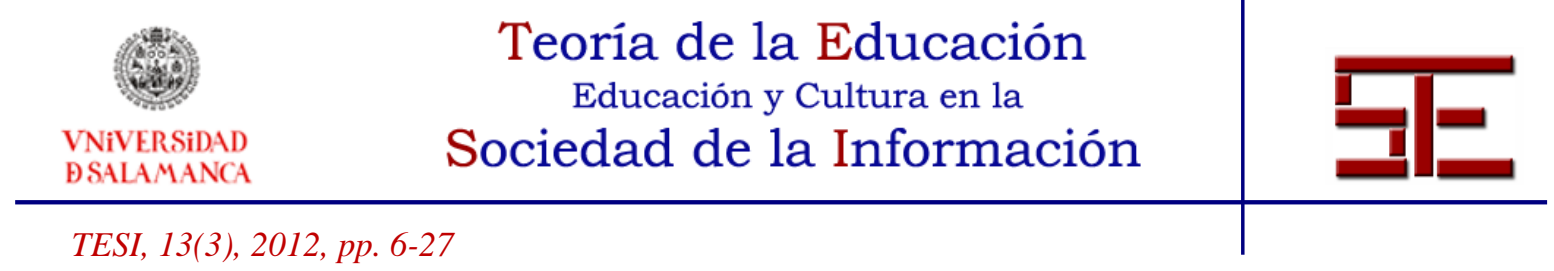

Las actividades de capacitación en línea son posibles en el tanto los educadores cuenten con los recursos tecnológicos para realizar los ensayos o ejercicios propuestos y la conexión a Internet sea estable. La mayor riqueza y aprovechamiento de los conocimientos se consiguen combinando ambas modalidades, presencial y en línea. Los espacios para el intercambio, el planteamiento de problemas y propuesta de soluciones son muy usados y efectivos.

La oferta de capacitación debe ser variada y siempre en función de las necesidades de conocimiento temático y metodológico que los educadores requieran para lograr con éxito los resultados de la propuesta. Periodos concentrados de 40 horas y distanciados a lo largo del año han resultado muy efectivos en nuestro caso. En igual sentido, debe garantizarse la continuidad de los profesionales de manera que con el tiempo ganen especialidad en la materia y puedan conformar grupos de profesionales que podrían compartir e intercambiar sus experiencias con otros colegas que inician o se integran al proyecto conforme éste crece y se expande.

\section{4.- Seguimiento o apoyo a la acción docente}

En cuanto al seguimiento, entendido como la acción de apoyar y orientar al docente en su salón de clase, es otro elemento esencial y requerido. Para ello es necesario disponer de asesores o personal especializado en el campo de la robótica, la investigación y la educación, que conocen muy bien la propuesta pedagógica, pero también cuentan con experiencia desde la práctica trabajando con estudiantes. Esa combinación facilitará un apoyo más efectivo porque podrá ofrecer insumos con conocimiento de causa. En el seguimiento lo ideal es que el educador sienta el apoyo y la confianza de quienes le asesoran para que pueda plantear sin temores sus debilidades y dificultades en la ejecución práctica.

Dependiendo de la magnitud del proyecto educativo, la organización geografía y la cantidad de educadores participantes es fundamental disponer de los medios electrónicos o recursos financieros para monitorear el proyecto globalmente. Esto facilita la toma de decisiones y permite construir una visión más cercana de los resultados y necesidades que el proyecto está necesitando. Igualmente este tipo de estudio ayuda a definir los rumbos y las decisiones hacia donde debe conducirse el proyecto, así como la detección de debilidades y puntos de mejora.

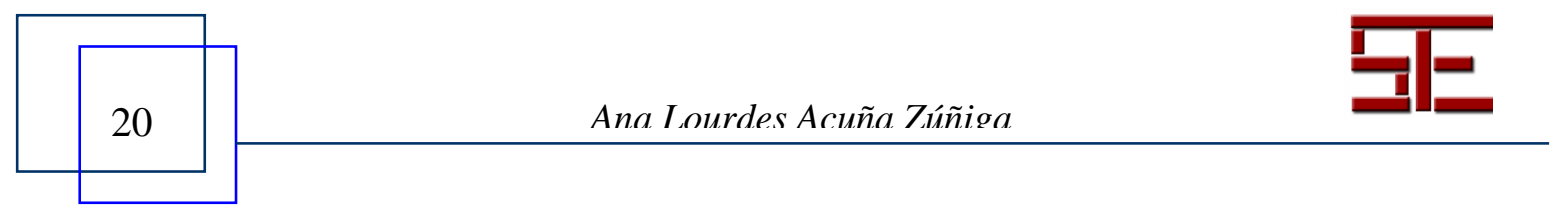




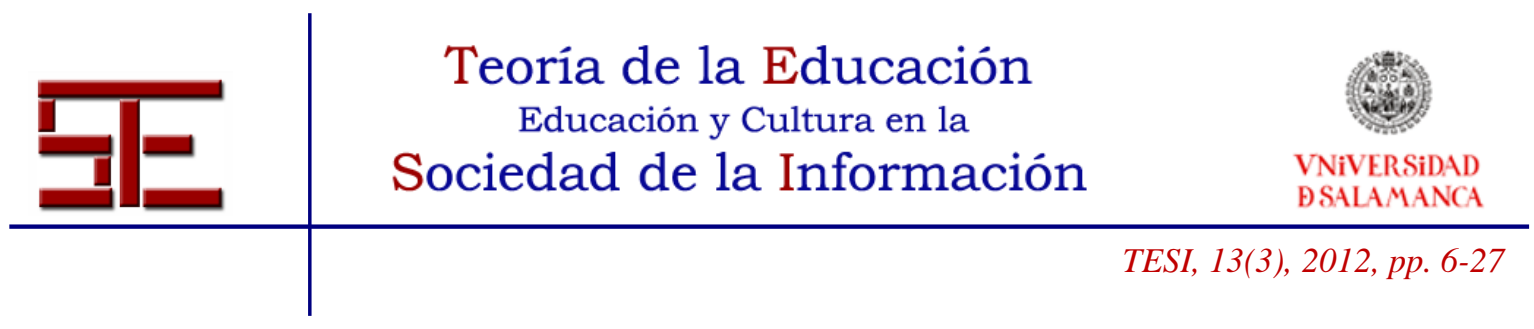

Al igual que la propuesta pedagógica todo proyecto educativo deberá crear sus marcos de seguimiento y evaluación de proceso y resultados. Con ese marco será más fácil que los educadores reciban en sus contextos de trabajo el soporte, pedagógico, requerido para concentrar sus acciones en el desarrollo de las capacidades esperadas para la población que se beneficia. Y facilitará la recolección de evidencias, productos y resultados que dan cuenta del avance e incidencia que el proyecto está teniendo, al tiempo que es posible detectar las debilidades y hacer las enmiendas necesarias.

\section{5.- Un respaldo político, administrativo y financiero}

La robótica como área de conocimiento nueva requiere del respaldo financiero y académico a largo plazo. Probablemente si emprendiéramos un estudio para reunir el conocimiento vinculado a la robótica que integre todos sus campos de acción posiblemente estemos muy cerca de una categorización muy similar a una ingeniería. Por esa razón, los proyectos educativos o de enseñanza de la robótica con estudiantes o educadores no pueden ser cortos y esporádicos, sino sostenidos y continuos. Cuando los proyectos educativos nacen bajo el respaldo y cobija de programas que se han consolidado, se tiene la ventaja de que también permean los proyectos educativos que inician y probablemente éstos tienen mejores oportunidades de consolidarse, sobre aquellos que se gestan en procesos o programas de corto plazo.

Si no se cuenta con un respaldo financiero y administrativo de largo plazo, estaríamos confinados a mostrar solo un grano de mostaza en un campo de conocimiento inmenso que está por descubrirse. Lo que se quiere decir es que todo proyecto educativo que se geste debe considerar desde sus inicios los medios para la sostenibilidad que le darán el respaldo financiero y administrativo en un tiempo razonable. De lo contrario no hay forma de lograr los alcances ni la incidencia esperada en la población. Todo proceso educativo que busca una formación particular en sus individuos requiere tiempo para concretarse.

Un cambio cualitativo que estamos promoviendo en Costa Rica es conseguir el aval político y académico para incluir robótica como parte de la oferta curricular cotidiana, tanto a nivel de enseñanza básica como universitaria, algo similar a lo que ya consiguió la informática educativa. Actualmente los proyectos de robótica educativa benefician a un porcentaje muy bajo de los estudiantes de primaria y secundaria, la meta sería elevar esa cobertura en los próximos años e incluir la especialidad a nivel secundario y universitario.

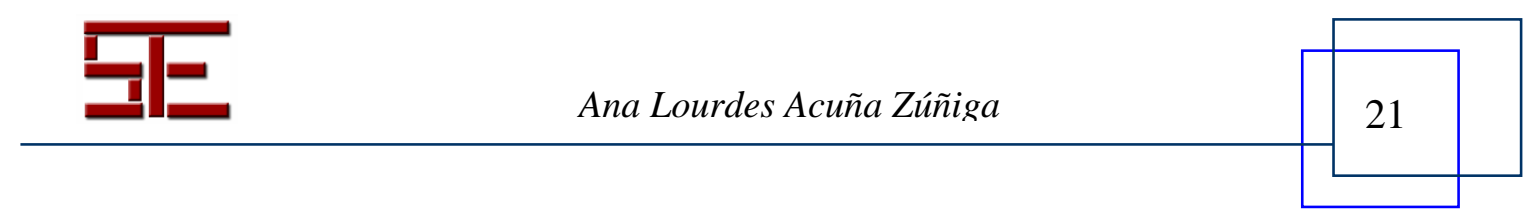




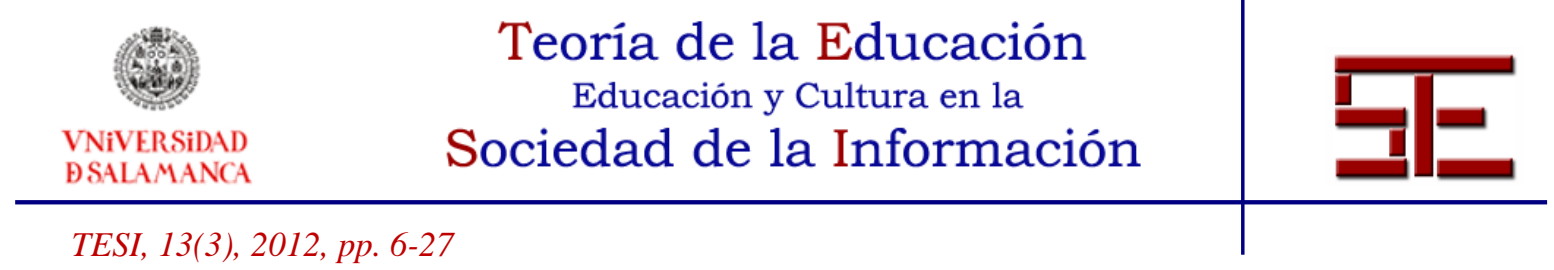

Un respaldo político, administrativo y financiero sostenido favorece el crecimiento y contribuye a la calidad de cualquier proyecto educativo, ofreciendo un contexto ideal para innovar o incorporar variantes y otros recursos que mejoren aun más el proceso de aprendizaje de los estudiantes.

\section{6.- HABILIDADES Y ROBÓTICA}

Retomando el tema de las capacidades a las que deben apuntar los proyectos educativos que dan inicio con robótica, uso como referencia las investigaciones de enGauge ${ }^{\circledR}$ (2003: 14) que se han concentrado en determinar las habilidades necesarias para preparar exitosamente a los estudiantes para la vida, el aprendizaje y el trabajo en una sociedad basada en el conocimiento. Este estudio presenta un planteamiento en categorías que agrupa esas habilidades y su relación con los contextos de aprendizaje que incluyen la robótica, éstas son:

Alta productividad: posibilidades de creación que se poseen para insertarse con éxito en una obra productiva.

Mentalidad creativa: La habilidad para aplicar las tecnologías digitales en situaciones sostenidas y complejas, y para comprender las consecuencias que de éstas se derivan.

Comunicación eficaz: trabajo en equipo y colaborativo, habilidades interpersonales, responsabilidad social, personal y cívica, comunicación interactiva.

Era digital: conoce y comprende los conceptos científicos necesarios para tomar decisiones, usa el lenguaje y el cálculo en el trabajo y en la sociedad para alcanzar las metas personales y para desarrollar conocimiento. Tiene conocimiento de lo que es la tecnología, involucra sus usos eficientes y eficazmente, toma decisiones al identificar problemas económicos, interpreta, usa y crea imágenes, videos y medios visuales. Busca rutas y nuevos escenarios para determinar medios y alcanzar fines.

Atendiendo el llamado de atención, Perkins en sus planteamientos sobre el Enfoque para la comprensión, dice que, en los últimos años se ha hablado mucho en la educación de las habilidades de pensamiento crítico y creativo, habilidades de resolución de problemas, etcétera; las cuales sin duda son muy importantes, pero el mero hecho de poseer una habilidad no garantiza que se use. Dice que "para que las habilidades se conviertan en parte de la conducta cotidiana deben cultivarse en un medio que las valore y apoye, de lo contrario, las habilidades de pensamiento de los alumnos tenderán a desaparecer en una cultura escolar que no estimule el pensamiento" (Perkins, 2006: 2).

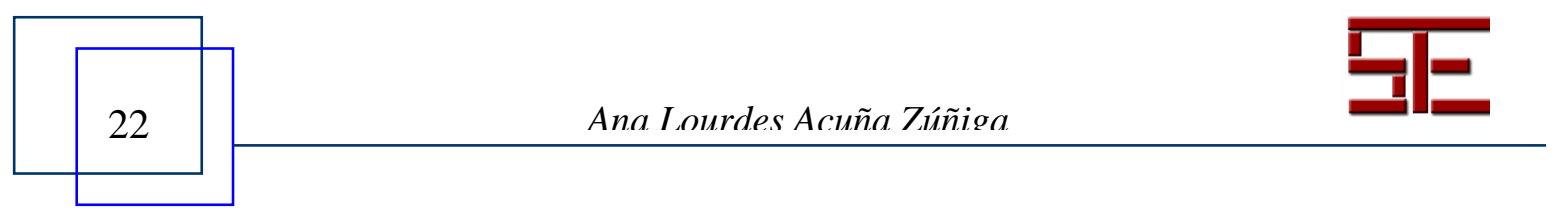




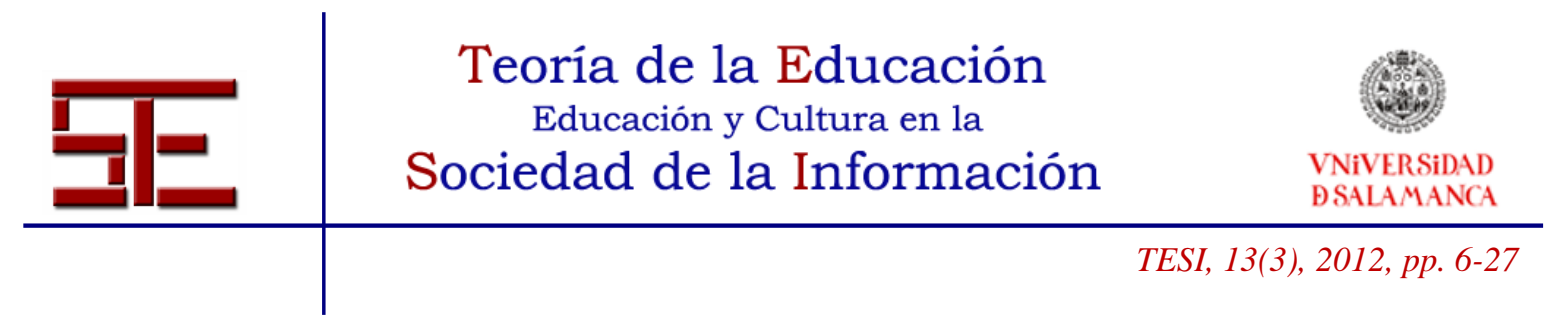

Apoyados en los resultados de nuestra experiencia sabemos que la robótica educativa posibilita los contextos ideales para que, tanto estudiantes como educadores consoliden en la acción y el pensamiento un conjunto de habilidades como las propuestas por EnGauge ${ }^{\circledR}$ y condicionadas por Perkins. La tabla siguiente presenta las habilidades que en nuestros contextos de aprendizaje hemos observado consolidarse en nuestros estudiantes al contactarse con nuestra propuesta de robótica educativa:

Tabla 1. Habilidades asociadas a la robótica educativa observadas en estudiantes

\begin{tabular}{|c|c|c|c|}
\hline Alta productividad & Comunicación eficaz & Era digital & Mentalidad creativa \\
\hline $\begin{array}{l}\text { Planean, organizan y } \\
\text { alcanzan, eficiente y } \\
\text { eficazmente las metas } \\
\text { del proyecto o la } \\
\text { propuesta de solución } \\
\text { al problema } \\
\text { detectado. }\end{array}$ & $\begin{array}{l}\text { Crean, planifican y } \\
\text { desarrollan proyectos } \\
\text { en grupo. Trabajan } \\
\text { juntos para resolver } \\
\text { problemas. }\end{array}$ & $\begin{array}{l}\text { Programan } \\
\text { controlan } \\
\text { producciones } \\
\text { usando lenguajes de } \\
\text { programación } \\
\text { especializados para } \\
\text { hacer robótica. }\end{array}$ & $\begin{array}{l}\text { Modifican sus } \\
\text { actitudes, conductas } \\
\text { y comprensiones } \\
\text { para adaptarse a lo } \\
\text { requerido o planeado }\end{array}$ \\
\hline $\begin{array}{l}\text { Priorizan áreas de } \\
\text { trabajo, diseñan y } \\
\text { crean sus prototipos } \\
\text { de solución o sus } \\
\text { simulaciones. }\end{array}$ & $\begin{array}{lr}\text { Comparten } & \text { y } \\
\text { enseñan a otros lo } \\
\text { que saben, ayudan a } \\
\text { resolver problemas } \\
\text { que otros } \\
\text { compañeros } \\
\text { enfrentan. }\end{array}$ & $\begin{array}{l}\text { Usan gran variedad } \\
\text { de herramientas y } \\
\text { recursos para crear } \\
\text { sus producciones: } \\
\text { escalas, seguetas, } \\
\text { catines, lenguajes } \\
\text { de programación y } \\
\text { creación de WEBs. }\end{array}$ & $\begin{array}{l}\text { Administran el } \\
\text { tiempo, los recursos } \\
\text { y los esfuerzos. } \\
\text { Evalúan la calidad de } \\
\text { sus productos. }\end{array}$ \\
\hline $\begin{array}{l}\text { Anticipan } \\
\text { contingencias } \\
\text { critican } \\
\text { producciones. }\end{array}$ & $\begin{array}{l}\text { Están dispuestos a } \\
\text { asumir diferentes } \\
\text { roles en los grupos } \\
\text { de trabajo, a fin de } \\
\text { conseguir las metas }\end{array}$ & $\begin{array}{l}\text { Usan e identifican } \\
\text { operadores } \\
\text { mecánicos en la } \\
\text { construcción de las } \\
\text { maquinas } \\
\text { compuestas y } \\
\text { efectos en } \\
\text { transmisión la } \\
\text { transformación del } \\
\text { movimiento. }\end{array}$ & $\begin{array}{l}\text { Están deseosos de } \\
\text { conocer e indagar. } \\
\text { Están dispuestos a } \\
\text { cometer errores. }\end{array}$ \\
\hline $\begin{array}{lr}\text { Valoran } & \text { los } \\
\text { resultados } & \text { para dirigir }\end{array}$ & $\begin{array}{r}\text { respeto, } \\
\mathrm{y}\end{array}$ & $\begin{array}{l}\text { Identifican } \\
\text { aprovechan }\end{array}$ & $\begin{array}{l}\text { Planean, piensan y } \\
\text { toman en cuenta los }\end{array}$ \\
\hline
\end{tabular}

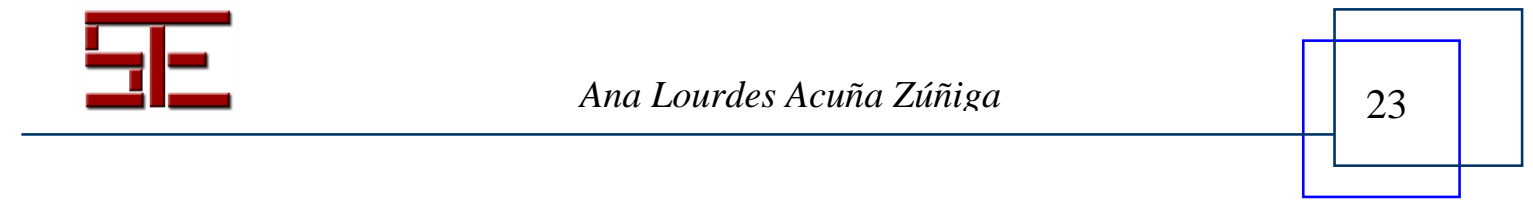




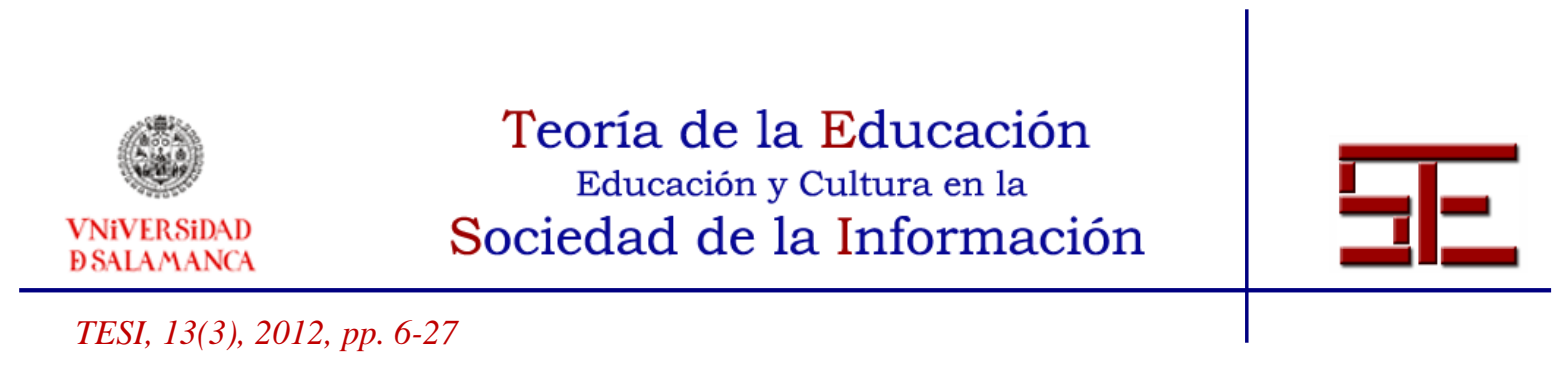

\begin{tabular}{|c|c|c|c|}
\hline $\begin{array}{l}\text { o alinear las facetas } \\
\text { del proyecto. }\end{array}$ & $\begin{array}{l}\text { confianza entre ellos } \\
\text { y con sus maestros. }\end{array}$ & $\begin{array}{l}\text { distintas fuentes de } \\
\text { información. } \\
\text { Textos, tecnologías } \\
\text { personas, videos, } \\
\text { sonidos. }\end{array}$ & $\begin{array}{l}\text { planes que se han } \\
\text { propuesto. }\end{array}$ \\
\hline $\begin{array}{l}\text { Crean productos } \\
\text { pertinentes y de alta } \\
\text { calidad atendiendo lo } \\
\text { planeado }\end{array}$ & $\begin{array}{l}\text { Se comprometen con } \\
\text { una meta compartida } \\
\text { y aceptan la } \\
\text { responsabilidad del } \\
\text { trabajo en equipo. }\end{array}$ & $\begin{array}{l}\text { Comprenden los } \\
\text { elementos básicos } \\
\text { de las producciones } \\
\text { robóticas: } \\
\text { percepción, } \\
\text { razonamiento, } \\
\text { comportamiento. }\end{array}$ & \begin{tabular}{ll} 
Crean & \multicolumn{2}{c}{ productos } \\
originales y nuevos \\
en función de la \\
necesidad que \\
plantea
\end{tabular} \\
\hline $\begin{array}{l}\text { Usan recursos } \\
\text { tecnológicos para } \\
\text { hacer robótica, así } \\
\text { como, textos, fotos y } \\
\text { video para agregar } \\
\text { valor a sus productos. }\end{array}$ & $\begin{array}{l}\text { Comparten sus } \\
\text { conocimientos } y \\
\text { recursos con otros } \\
\text { miembros del grupo }\end{array}$ & $\begin{array}{lll}\text { Evalúan } & & \text { los } \\
\text { procesos } & \text { y } & \text { los } \\
\text { productos } & \text { de } & \text { sus } \\
\text { actividades } & & \end{array}$ & $\begin{array}{l}\text { Emprenden } \\
\text { soluciones } \\
\text { situaciones que no } \\
\text { resultan obvias }\end{array}$ \\
\hline $\begin{array}{l}\text { Entienden y pueden } \\
\text { valorar y criticar la } \\
\text { utilidad de los } \\
\text { productos creados. }\end{array}$ & $\begin{array}{l}\text { Diseñan y rediseñan } \\
\text { soluciones }\end{array}$ & $\begin{array}{l}\text { Aplican los } \\
\text { principios del } \\
\text { diseño tecnológico } \\
\text { en sus productos }\end{array}$ & $\begin{array}{l}\text { Consideran } \\
\text { hipótesis, hacen } \\
\text { inferencias, } \\
\text { evalúan y mejoran } \\
\text { sus producciones }\end{array}$ \\
\hline
\end{tabular}

Fuente: Producción propia.

\section{7.- ROBÓTICA E INNOVACIÓN}

En el sector educativo hablamos de innovación como un proceso que permite incorporar cambios en las formas de hacer, de pensar y de vivir. Regularmente las situaciones que son valoradas como innovaciones surgen a partir de la necesidad de resolver problemas particulares o de atender necesidades y demandas. Es común que ocurran y no sean identificadas; sin embargo, un factor a observar es si, realmente, la iniciativa que se gestó se está consolidando y si acepta con facilidad los cambios. "Una innovación es un proceso de gestión de cambios específicos, en ideas o instrumentos, hasta su consolidación" (De la Torre, 1998: 19).

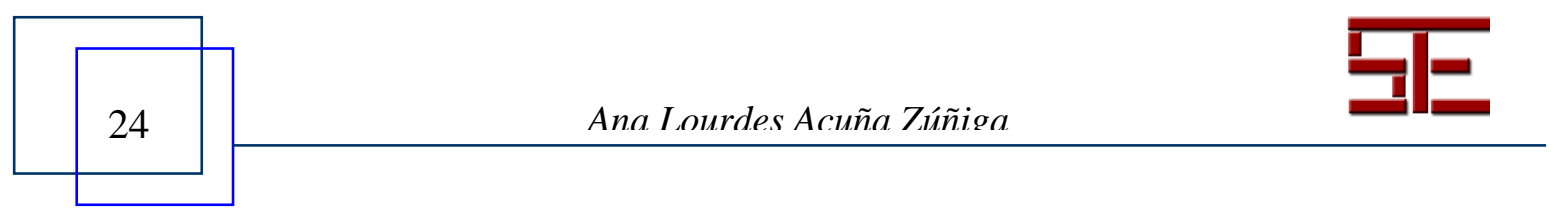




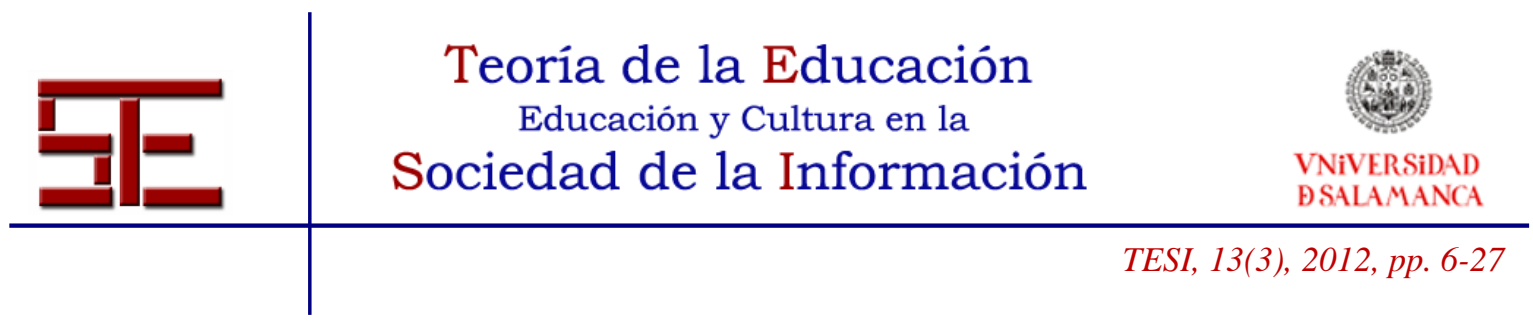

La robótica como proyecto educativo se puede considerar innovación en tanto implique y beneficie a las personas para las cuales fue creada, y sea asumida e incorporada como práctica cotidiana. Su razón de ser podrá ser instaurada si los educadores y estudiantes muestran y conservan actitudes y sentimientos sostenidos a lo largo del tiempo y mientras el proyecto educativo se encuentre en ejecución.

Un indicador de que la robótica es el resultado del motor de innovación es mirar y evaluar el cambio en las personas, en las ideas y actitudes, en las relaciones, modos de actual pensar y hacer de los involucrados. Si eso es visible desde la práctica y con evidencia confirmada, entonces estamos ante una innovación.

\section{8.- CONCLUSIONES}

La robótica educativa es un área de conocimiento nueva que está incursionando rápidamente en el sector educativo formal universitario, como una especialidad de formación o en el sector de la enseñanza primaria y como experiencias o proyectos educativos que intentan acercar a las poblaciones jóvenes a estos conocimientos.

Como preámbulo a su implantación es necesario tener en cuenta factores de índole pedagógica, administrativa y técnica. En el campo pedagógico resulta relevante considerar aspectos de apropiación que se desean promover y la determinación de habilidades que se fortalecen a partir de la experiencia. Consideraciones sobre el ambiente de aprendizaje, la capacitación y el seguimiento o acompañamiento a los educadores marcan la diferencia.

En el mercado existe gran variedad de recursos o alternativas tecnológicas con diferentes potencialidades, su elección dependerá de los desempeños que busque fortalecer el proyecto educativo.

La gran variedad de lenguajes de programación, tipos de interfaces y controladores y de recursos constructivos está a disposición y con variedad de costos, sin embargo, una buena elección es aquella que considere en primer lugar la población meta a beneficiar, la cantidad de estudiantes que se atenderá en simultáneo y periódicamente así como el tipo de proyectos que se espera que los estudiantes diseñen y concreten con esos recursos.

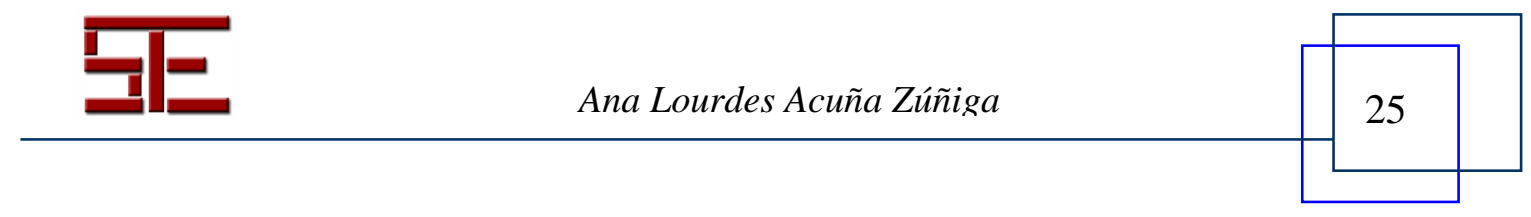




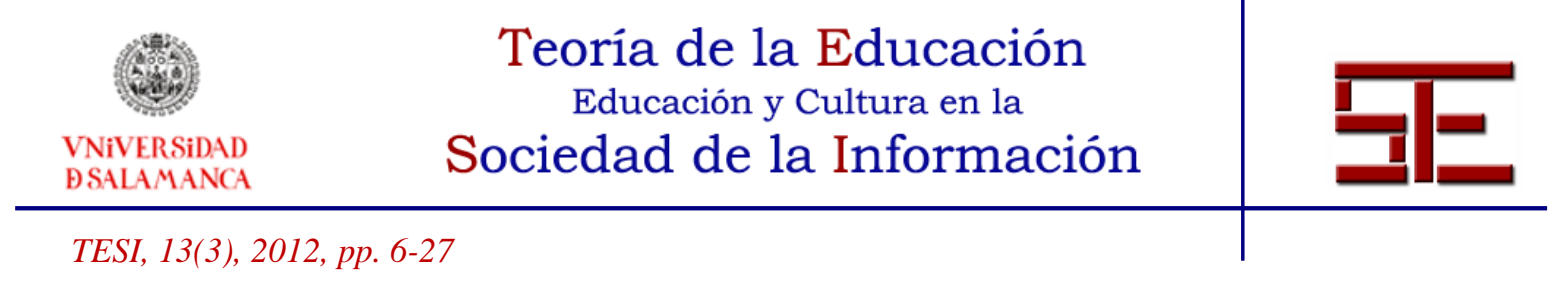

Una buena razón para considerar la robótica como un motor de innovación en los contextos educativos está asociada a las posibilidades que brinda para insertar cambios relevantes en las formas de enseñar y aprender de los estudiantes y la factibilidad que muestra para consolidarse e incorporarse como una práctica regular y cotidiana en los procesos de enseñanza.

Es imposible emprender un proyecto educativo que incluya la robótica como recurso de aprendizaje para apoyar los procesos de pensamiento y creación sino, se cuenta con: un marco pedagógico sólido y de fácil comprensión, una caracterización del ambiente de aprendizaje que detalle las formas de relación entre las personas y de éstas con los recursos, un proceso de capacitación acorde con la evolución tecnológica y educativa, y un proceso de seguimiento permanente. Siempre y cuando se cuente con el respaldo político y financiero justo que las poblaciones infantiles y jóvenes necesitan.

\section{REFENCIAS BIBLIOGRÀFICAS}

Acuña, A. (2004). Robótica y aprendizaje por Diseño. EDUCACIÓN AÑO XLVIIIXLIX, 139-140, I-II, [en línea] http://www.educoas.org/portal/bdigital/laeducacion/home.html. [consulta: febrero 2012].

De la Torre, S. (1998). Cómo innovar en los centros educativos. Estudios de casos. Madrid, España: Editorial escuela española

enGauge $\AA$. (2003). 21st Century Skills: Literacy in the Digital Age [en línea] <http://www.ncrel.org/engauge/skills/skills.htm [consulta: junio 2006].

Fundación Omar Dengo Educación y tecnologías digitales (2006). Cómo valorar su impacto social y sus contribuciones a la equidad. FOD - 1 a. ed. San José.

Perkins, D. (2006). Hacia una cultura de pensamiento. Conferencia. [en línea] http://www.ellibro.com.ar/32feria/educativas/html/archivo/conferencias/perkins_david.h tml. [Buenos Aires, Argentina] [consulta: febrero 2012].

Papert, P. (2003). La máquina de los niños. Replanterase la educación en la era de los ordenadores. Paidós, Barcelona, España:151-169

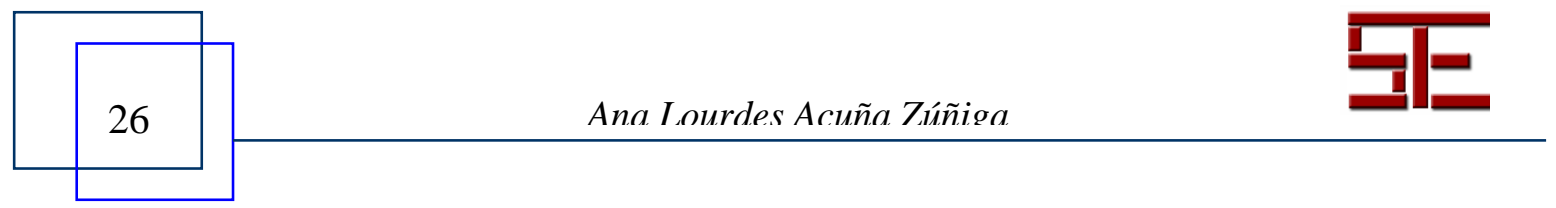




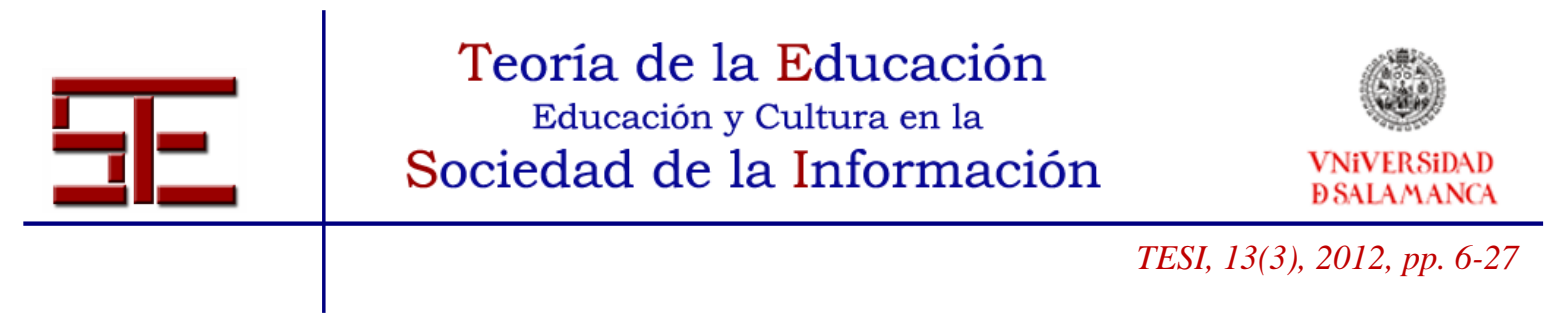

- Notas

${ }^{1}$ World Links. Opening a world thorgh learning [en línea] http://www.world-links.org/ [consulta: marzo 2012].

${ }^{2}$ Proyecto Ciber@prendiz: Aplicaciones del Internet para el Aprendizaje Educativo [en línea] http://www.ciberaprendiz.org/es/intro.html [consulta: marzo 2012].

${ }^{3}$ Intel Corporation. (2012) Programa Intel® Educar [en línea] / [consulta: marzo 2012]. http://www.intel.com/education/la/es/programas/IntelEducar/index.htm[consulta: marzo 2012].

${ }^{4}$ Syr Silvia. (2012) First Lego League Robotics in the Classroom. [en línea] http://www.firstlegoleague.org/ [consulta: marzo 2012].

${ }^{5}$ Federation Robo Cup (2012). What is Rob Cup ?. . [en línea] http://www.robocup.org/ consulta:marzo 2012].

${ }^{6}$ NASA ( 2012) The robotics alliance proyect . [en línea] http://robotics.nasa.gov/ [consulta: marzo 2012].

${ }^{7}$ Turkbak F. \&Berg, R. (2002). Robotic Design Studio: Exploring the Big Ideas of Engineering In a Liberal Arts Environment. [en línea] http://www.wellesley.edu/Physics/Rberg/papers/RDSJSET-final.pdf [consulta: marzo 2012].

${ }^{8}$ Fundación Omar Dengo. Robótica y Aprendizaje por diseño [en línea] http://www.fod.ac.cr/robotica/. [consulta: marzo 2012].

Para citar el presente artículo puede utilizar la siguiente referencia:

Acuña Zúñiga, A. L. (2012). Diseño y administración de proyectos de robótica educativa: lecciones aprendidas. Revista Teoría de la Educación: Educación y Cultura en la Sociedad de la Información. 13(3), 6-27 [Fecha de consulta: dd/mm/aaaa]. http://campus.usal.es/ revistas_trabajo/index.php/revistatesi/article/view/9126/9355

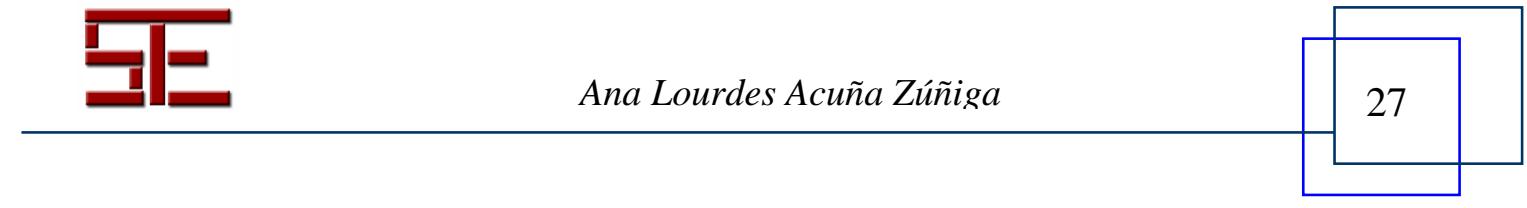

